\title{
Biodiversidade florística ameaçada pelo uso intensivo de pastagens, no município de Palmeirina - PE.
}

Floristic biodiversity threatened by deforestation for the introduction of pastures in the municipality of Palmeirina - PE .

Machado $^{1}$, J. R. A.; Silva ${ }^{1}$ N. G.; Duarte ${ }^{1}$, C. C.

Jose.roberto.alves.machado@hotmail.com

\begin{abstract}
Resumo
Objetivou-se analisar e identificar a diversidade fitogeográfica em Palmeirina- PE. Esta que está sendo ameaçada pelo intenso desmatamento impulsionado pela cultura do pasto. Foram utilizadas imagens do satélite LandSat 8 datadas de 14 de Junho de 2014, tratadas e processadas por meio do Software ArcGis 10.2.2, conciliando-se com técnicas de Sensoriamento Remoto através da classificação supervisionada (máxima verossimilhança). Buscou-se identificar a potencialidade arbóreo-arbustiva, quantificando e reconhecendo sua biodiversidade. Feito a análise, a vegetação foi classificada em: vegetação arbórea de grande porte, vegetação arbórea de pequeno porte, vegetação rasteira e solo exposto. Também diagnosticou-se que o dossel apresentava características biogeográficas de Mata Atlântica e de Caatinga, pois o objeto de estudo fica na transição das mesorregiões Mata Sul e Agreste Meridional.
\end{abstract}

Palavras-chave: pastagem, biodiversidade e desmatamento.

\begin{abstract}
This study aimed to analyze and identify the phytogeographic diversity in Palmeirina- PE . This being threatened by massive deforestation driven by pasture culture. Images from satellite Landsat 8 dated 14 June 2014, handled and processed through the Software ArcGis 10.2.2 if combining with Remote Sensing techniques through supervised classification ( Maximum Likelihood) . We sought to identify the trees and shrubs potential, quantifying and recognizing its biodiversity. Made analysis, vegetation was classified as large arboreal vegetation, small arboreal vegetation, underbrush and exposed soil, also diagnosed that the canopy had biogeographical characteristics of the Atlantic Forest and Caatinga as the object of study it is in transition from mesoregions South Forest and South Agreste .
\end{abstract}

Keywords: grazing, biodiversity e deforestation

\section{INTRODUÇÃO}

Atualmente, muito se tem debatido sobre as relações homem/natureza e os efeitos desta sobre o meio ambiente. A questão da vegetação e de sua interação com outros sistemas naturais impele a uma recrudescência do tema pelo tamanho significativo de sua importância, levando em consideração a interdisciplinaridade da problemática ambiental, esta que nunca medrara tanto entre nós como nos últimos tempos (SALES, 2011).

Historicamente, esse bioma foi o primeiro a sofrer a ação predatória do homem europeu com a extração do pau brasil, cujo produto deu nome ao nosso país, evidenciando-se como o recurso pioneiro na intensa exploração e consequente devastação biogeográfica da área. Como afirma o historiador Prado Júnior, 


\begin{abstract}
"Espalhada por larga parte da costa brasileira, e com relativa densidade, observou-se uma espécie vegetal semelhante a outra já conhecida no Oriente, e de que se extraía uma matéria corante empregada na tinturaria. Tratava-se do pau-brasil, mais tarde batizado cientificamente com o nome de Caesalpinia echinata. Os primeiros contatos com o território que hoje constitui o Brasil, devem-se àquela madeira que se perpetuaria no nome do país." (PRADO JÚNIOR, 1982, p. 24- 25).
\end{abstract}

A cultura de criação de animais tem seu início com a introdução do gado na economia açucareira e daí a sua permanência nas atividades do cotidiano do povo nordestino. A respeito das atividades econômicas no nordeste, Prado Junior (1978) descreve que "sua base econômica será sempre a pecuária, e os grandes focos de irradiação continuarão sendo Bahia e Pernambuco."

O espaço pernambucano com a introdução do gado nas atividades econômicas passa a ter nova caracterização, abrindo assim a era da pecuária. Hoje, Pernambuco, mais especificamente o Agreste Meridional, tem como uma de suas principais atividades econômicas, a produção de leite. Este cenário se constituiu ao longo da história do desenvolvimento pernambucano. A atividade leiteira tem seu aspecto positivo no que concerne ao desenvolvimento econômico, mas em contrapartida tem afetado muito o ambiente, reduzindo a biodiversidade e influenciando na degradação do solo (DA SILVA, 2010)

Diante desses aspectos, o presente trabalho busca identificar e mapear as áreas de vegetação arbórea suprimidas pela intensa cultura do pasto, no município de Palmeirina - PE e diagnosticar através de consultas bibliográficas e reconhecimento das mesmas em atividades de campo, com o auxílio do CEPAN - Centro de Pesquisas Ambientais do Nordeste - para reconhecimento da riqueza fitogeográfica da área, esta que apresenta pequenos fragmentos remanescentes de mata atlântica empobrecidos e alterados na sua composição florística, mas que sem nenhuma política de conservação destes aspectos físicos.

O município tem uma característica física e climática particular, estando a barlavento do planalto da Borborema (constituindo o que chamamos de área de brejo) e recebendo uma maritimidade do litoral, vinda da Mata Sul. Contudo, essa posição privilegiada pelas características do aspecto intermediário de Zona da Mata e de Agreste é que lhe proporciona um caráter físico singular, contendo solos férteis. 


\section{METODOLOGIA}

\subsection{Localização e Limites}

Esta pesquisa tem como área de estudo a cidade de Palmeirina - PE (Figura 1), localizada na mesorregião Agreste Meridional e na Microrregião de Garanhuns do Estado de Pernambuco, limitando-se a norte com São João e Angelim, a sul com Correntes e o Estado das Alagoas, a leste com Canhotinho, e a oeste com Garanhuns. A sede do município tem uma altitude aproximada de 531 metros e coordenadas geográficas de $09^{\circ} 00^{\prime} 16^{\prime \prime}$ de latitude sul e $36^{\circ} 19^{\prime} 33$ " de longitude oeste, distando $252 \mathrm{~km}$ da capital Recife, cujo acesso é feito pela BR-101 e PE-126/187.

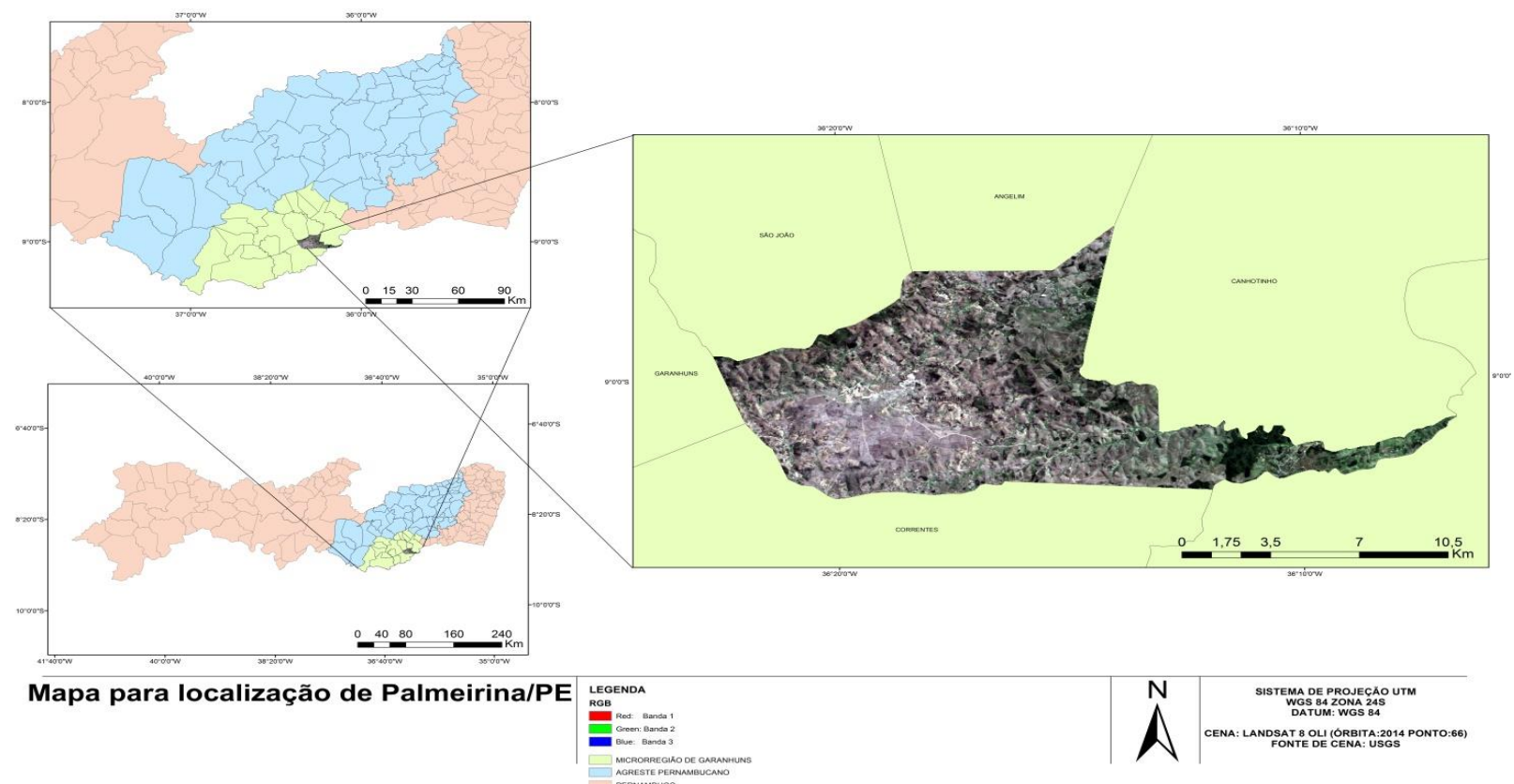

Figura 01. Mapa de localização da área de estudo. Município de Palmerina, Pernambuco. Fonte: Desenvolvido pelo autor.

A metodologia utilizada para o desenvolvimento da pesquisa divide-se de acordo com os seguintes itens: Levantamento Fitogeográfico e Mapeamento da Vegetação.

\subsection{Levantamentos fitogeográfico}

O trabalho de análise das características fitogeográficas da área se baseia em leituras das referências bibliográficas dos vários autores acerca do tema e através das contribuições de AndradeLima (2014), CEPAN - Centro Pesquisas Ambientais do Nordeste - e pelo levantamento de espécies de plantas feito por meio de entrevistas não estruturadas, inquirindo os informantes sobre 
as plantas existentes no local e o trabalho de campo, pois este é fundamental para que a fitogeografia tenha eficiência nos dados (DE OLIVEIRA COSTA, 2010). Tratou-se de analisar in loco visando compreender a diversidade fitogeográfica da área, para a partir daí desenvolver um inventário florístico da área em questão.

\subsection{Mapeamento fitogeográfico}

Para a realização do mapeamento, foram utilizadas imagens do satélite LandSat 8 datadas de 14 de Junho de 2014, tratadas e processadas por meio do Software ArcGis 10.2.2, conciliando-se com técnicas de Sensoriamento Remoto através da classificação supervisionada (máxima verossimilhança).

Através da técnica de mapeamento demonstrou-se como as características de uso e a ocupação da terra tem-se efetivado no município e quais as possíveis causas que esses possam ocasionar na composição da diversidade florística do município. Através de imagens de satélite, mostrou-se como a vegetação é distribuída e, por meio de fotografias "in loco", buscou-se fazer uma relação de quais espécies predominam e qual o capital natural que representam aos proprietários.

\section{RESULTADOS E DISCUSSÃO}

Palmeirina - PE encontra-se no paralelo entre os biomas Mata Atlântica e Caatinga, manifestando sua posição intermediária. Geograficamente, ela está inserida na região do Agreste Meridional, mas fisicamente ela abrange as características da Mata Sul de Pernambuco. Segundo Andrade-Lima (2007), a Zona da Mata de Pernambuco divide-se em sub-zonas: Mata Úmida; Mata Seca e Matas Serranas. Palmeirina localiza-se na Mata Úmida, caracterizada, por árvores perenifólias, alta exuberância, de folhagem verde-escuro, alta densidade de cipós e suas árvores têm o diâmetro do caule maior do que o comprimento; e por seu aspecto intermediário também agrega características de caatinga, contendo, espécies decíduas, caracterizadas pelos espinhos e grande abundância de Cactáceas e Bromeliáceas. Essa localização geográfica é que faz com que essa região tenha uma grande biodiversidade fitogeográfica, contendo um vasto número de 28 famílias, 43 gêneros e 45 espécies.

Através das pesquisas, das referências bibliográficas, do auxílio do CEPAN e de visitas a campo, reconheceu-se vasto poder florístico, juntamente com moradores munidos de ricos conhecimentos do senso comum, identificando espécies pelos seus nomes populares, dessa forma 
fizemos um levantamento sobre informações das mesmas. Daí a importância da comunidade rural que presencia e se manifesta como agentes contribuidores para a pesquisa científica. Feito isso, as espécies mencionadas pelos moradores, pelas bibliografias e o CEPAN, proporcionaram a elaboração de uma tabela contendo as principais espécies encontradas, algumas em maior abundância, outras ameaçadas de extinção (Tabela 01).

Tabela 01. Diversidade fitogeográfica Fonte: CEPAN, Andrade-Lima e entrevistas não estruturadas.

\begin{tabular}{|c|c|c|c|}
\hline FAMÍLIA & GÊNERO & ESPÉCIE & NOME POPULAR \\
\hline Alismaceae & Echinodoru & Echinodorus floribundus Seub & chapéu de couro \\
\hline Anacardiaceae & Schinus & Schinus therebinthifolius Raddi & Aroeira \\
\hline Anacardiaceae & Spondias & Spondias mombin L. & Cajá \\
\hline Anacardiaceae & Tapirira & Tapirira guianensis Aubl. & Pau pombo \\
\hline Anacardiaceae & Thyrsodium & Thyrsodium spruceanum Benth. & Caboatã de leite \\
\hline Annonaceae & Annona & Annona montana Macfad. & Aticum \\
\hline Annonaceae & Guatteria & Guatteria pogonopus Mart. & Mium \\
\hline Annonaceae & Xylopia & Xylopia frutescens Aubl. & Pindaíba branca \\
\hline Annonaceae & Xylopia & Xylopia ochrantha Mart. & Pimenta de macaco \\
\hline Apocynaceae & Aspidosperma & Aspidosperma discolor A. DC. & Pau falho \\
\hline Apocynaceae & Plumiera & Plumiera bracteata A. DC. & Banana de papagaio \\
\hline Apocynaceae & Himatanthus & $\begin{array}{l}\text { Himatanthus bracteatus (A. DC) } \\
\text { Woodson. }\end{array}$ & macaúba \\
\hline Arecaceae & Acrocomia & Acrocomia intumescens Drude. & Trapiá \\
\hline Brassicaceae & Crateva & Crateva tapia L. & Breu branco \\
\hline Burseraceae & Protium & $\begin{array}{l}\text { Protium heptaphyllum (Aubl.) } \\
\text { Marchand. }\end{array}$ & Oití-coró \\
\hline Chrysobalanaceae & Couepia & Couepia rufa Ducke. & pororoca \\
\hline Clusiaceae & Clusia & Clusia nemorosa G. Mey & bulandí \\
\hline Clusiaceae & Symphonia & Symphonia globulifera L.f. & Mamajuda preta \\
\hline Elaeocarpaceae & Sloanea & $\begin{array}{l}\text { Sloanea guianensis (Aubl.) } \\
\text { Benth. }\end{array}$ & cumichá \\
\hline Erythroxtlaceae & Erythroxylum & $\begin{array}{l}\text { Erythroxylum mucronatum } \\
\text { Benth. }\end{array}$ & \\
\hline Euphorbiaceae & Pogonophora & $\begin{array}{l}\text { Pogonophora schomburgkiana } \\
\text { Miers ex Benth. }\end{array}$ & Cocão branco \\
\hline Fabaceae & Andira & Andira fraxinifolia Benth. & Angelim mirim \\
\hline Fabaceae & Andira & Andira legalis (Vell.) Toledo & Angelim coco \\
\hline Fabaceae & Machaerium & $\begin{array}{l}\text { Machaerium hirtum (Vell.) } \\
\text { Stellfeld. }\end{array}$ & Bico de pato \\
\hline Fabaceae & Parkia pendula & $\begin{array}{l}\text { Parkia pendula (Willd.) Benth. } \\
\text { ex Walp. }\end{array}$ & visgueiro \\
\hline Fabaceae & Stryphnodendron & Stryphnodendron pulcherrimum & favinha \\
\hline
\end{tabular}




\begin{tabular}{|l|l|l|l|}
\hline Hypericaceae & Vismia & $\begin{array}{l}\text { (Willd.) Hochr. } \\
\text { Choisy guianensis (Aubl.) }\end{array}$ & lacre \\
\hline Lamiaceae & Aegiphila & $\begin{array}{l}\text { Aegiphila pernambucensis } \\
\text { Moldenke }\end{array}$ & salgueiro \\
\hline Lecythidaceae & Eschweilera & $\begin{array}{l}\text { Eschweilera ovata (Cambess.) } \\
\text { Mart. }\end{array}$ & biriba \\
\hline Lecythidaceae & Gustavia & Gustavia augusta L. & Pau fedorento \\
\hline Malpighiaceae & Henriettea & Henriettea succosa (Aubl.) DC. & candieiro \\
\hline Malvaceae & Byrsonima & Byrsonima sericea DC. & muricí \\
\hline Melastomaceae & Apeiba & Apeiba tibourbou Aubl. & Pau de jangada \\
\hline Melastomaceae & Miconia & Miconia prasina (Sw.) DC. & Sabiazeira \\
\hline Meliaceae & Guarea & Guarea guidonia (L.) Sleumer & Canjerana miúda \\
\hline Moraceae & Brosimum & $\begin{array}{l}\text { Brosimum guianense (Aubl.) } \\
\text { Huber }\end{array}$ & Leiteira vermelha \\
\hline Moraceae & Sorocea hilarii & Sorocea hilarii Gaudich. & Camaçari de leite \\
\hline Myrtaceae & Campomanesia & $\begin{array}{l}\text { Campomanesia dichotoma } \\
\text { (O.Berg) }\end{array}$ & guabiraba \\
\hline Myrtaceae & Psidium & Psidium guineense Sw. & araçá \\
\hline Rubiaceae & Psychotria & Psychotria carthagenensis Jacq. & Erva de rato \\
\hline Sapotaceae & Pradosia & $\begin{array}{l}\text { Pradosia lactescens (Vell.) } \\
\text { Radlk. }\end{array}$ & Mama de cabra \\
\hline Simaroubaceae & Simarouba & Simarouba amara Aubl. & Pau paraíba \\
\hline Siparunaceae & Siparuna & Siparuna guianensis Aubl. & Catingueira de paca \\
\hline Urticaceae & Pourouma & Pourouma guianensis Aubl. & Embaúba da mata \\
\hline Violaceae & Paypayrola & Paypayrola blanchetiana Tul. & mangue \\
\hline
\end{tabular}

A partir desses dados, percebe-se quão grande é o poder florístico do município, mas este vem sendo ameaçado pela intensa cultura da pastagem para a criação de gado. Feita a análise em campo verificou-se que os proprietários rurais usam a terra apenas como capital natural, ou seja, permanecerá apenas a cultura que lhes fornecer lucro, caso contrário será devastada e dará lugar a pastagem. Isso tem causado uma grande devastação na biodiversidade florística. Desde então, buscou-se identificar a potencialidade arbóreo-arbustiva, quantificando e reconhecendo sua biodiversidade.

A partir dessa análise do potencial arbóreo, buscou-se fazer um mapa de uso do solo para identificar o percentual de cada uso e relaciona-lo com o problema em questão: ameaça da 
biodiversidade. Assim, a vegetação foi classificada em: vegetação arbórea de grande porte, vegetação arbórea de pequeno porte, vegetação rasteira e solo exposto (Figura 02).

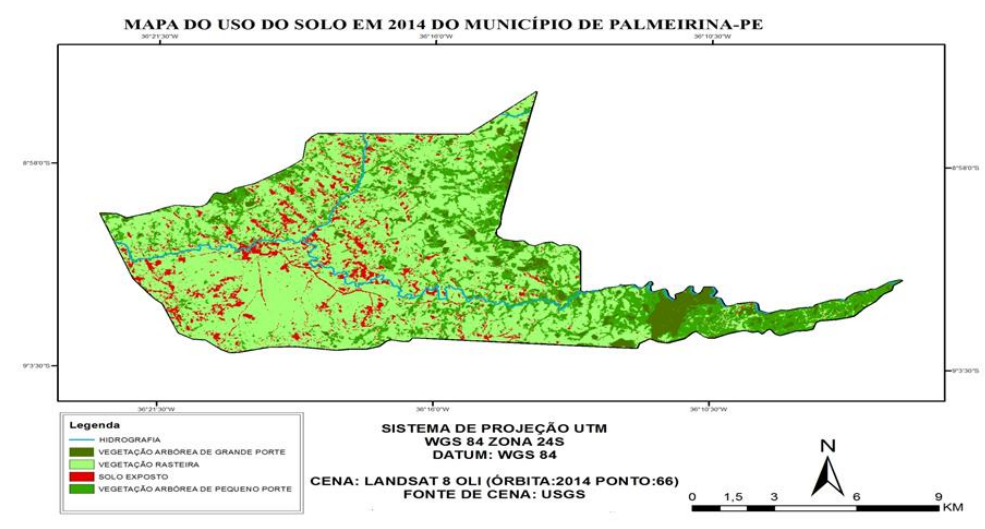

Figura 02. Mapa de uso do solo. Fonte: Autores.

Para elaborar o mapeamento, usou-se a técnica de classificação supervisionada com imagens de satélites indicando cada tipo de uso. A vegetação arbórea é a classe florística mais ameaçada do município, ocupando uma área de $9,045 \mathrm{Km}^{2}$ com um percentual de ocupação equivalente a $5,716 \%$, na maioria das vezes desmatadas sem fiscalização. A vegetação de pequeno porte caracteriza-se como matas secundárias e capoeiras, abrangendo uma área de 34,261 km², constituindo 21,654 \% do município. A vegetação rasteira caracterizada pela pastagem e se manifesta em abundância, pois possui grande influência na produção econômica do município, situando-se em $96,025 \mathrm{Km}^{2}$ e com um percentual de 60,392\%. O solo exposto concentra 12,041 $\mathrm{Km}^{2}$ e sua taxa é 7,796\%, essa área possui características degradas, por estarem sem proteção e certo grau de erosão (Tabela 02.)

Tabela 02. Área ocupada e percentual de cada classe identificada em Palmerina, PE

\begin{tabular}{|c|c|c|c|}
\hline Classes & $\begin{array}{c}\text { Área ocupada } \\
\left(\mathrm{Km}^{2}\right)\end{array}$ & Taxa de área ocupada & Figuras \\
\hline Vegetação de grande porte & 9,045 & $5,716 \%$ & Fig.3 \\
\hline $\begin{array}{c}\text { Vegetação arbórea de } \\
\text { Pequeno porte }\end{array}$ & 34,261 & $21,654 \%$ & Fig.4 \\
\hline Vegetação rasteira & 96,025 & $60,392 \%$ & Fig.5 \\
\hline Solo Exposto & 12,041 & $7,796 \%$ & Fig.6 \\
\hline Corpos d'Água & 6,264 & $3,959 \%$ & \\
\hline
\end{tabular}


Notoriamente, os proprietários rurais palmeirinenses visam sempre a lucratividade. Deste modo, a espécie que apresentar um capital natural irá permanecer no terreno, caso contrário, será devastada para a introdução de pastos. Espécies como Bowdichia virgilioides Kunth (Sucupira) Mimosa tenuiflora (Willd.) Poiret (Jurema Preta), Mimosa caesalpiniifolia (Sabiá), apresentam um capital natural, pois servem de estacas para o cercamento da propriedade. Através das imagens aéreas, obtidas através de drones, observa-se o predomínio da pastagem em relação aos vestígios de matas suprimidas pela atividade leiteira (figura 3).

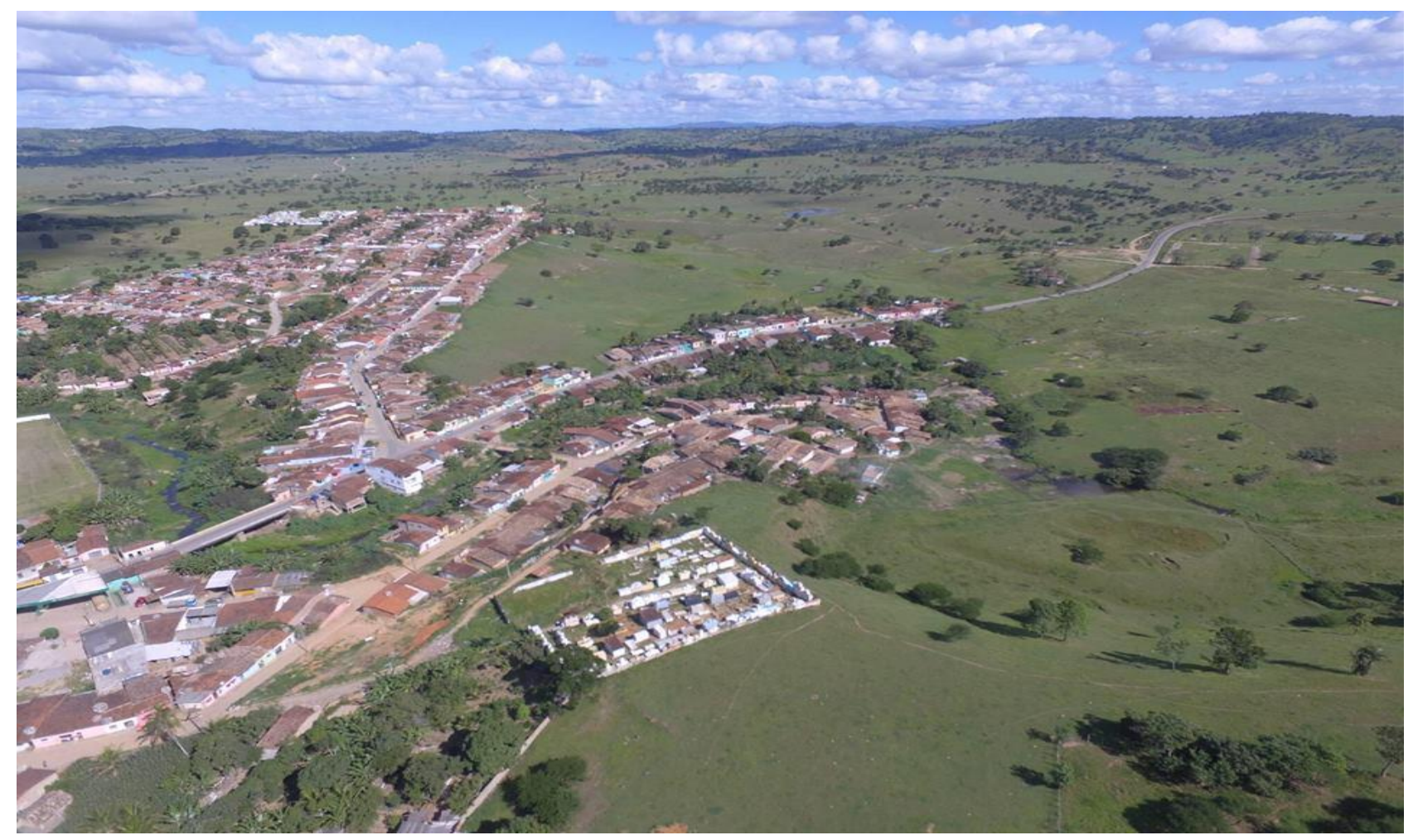

Figura 3. Vista aérea do município. Fonte: Autores.

Os conflitos ideológicos sobre biodiversidade sobressaem no embate entre produção e preservação, necessitando de estratégias negociáveis que norteiem a perspectiva do produzir e preservar conjuntamente, para que o primeiro possa ocorrer sem degradar o ambiente, impondo assim, o chamado desenvolvimento sustentável. Deste modo, afirma-se a necessidade de uma nova característica na produção agropecuária do município, uma produção voltada para o lucro, mas que mantenha-se um equilíbrio na diversidade, fato não observado na região (figura 4). 


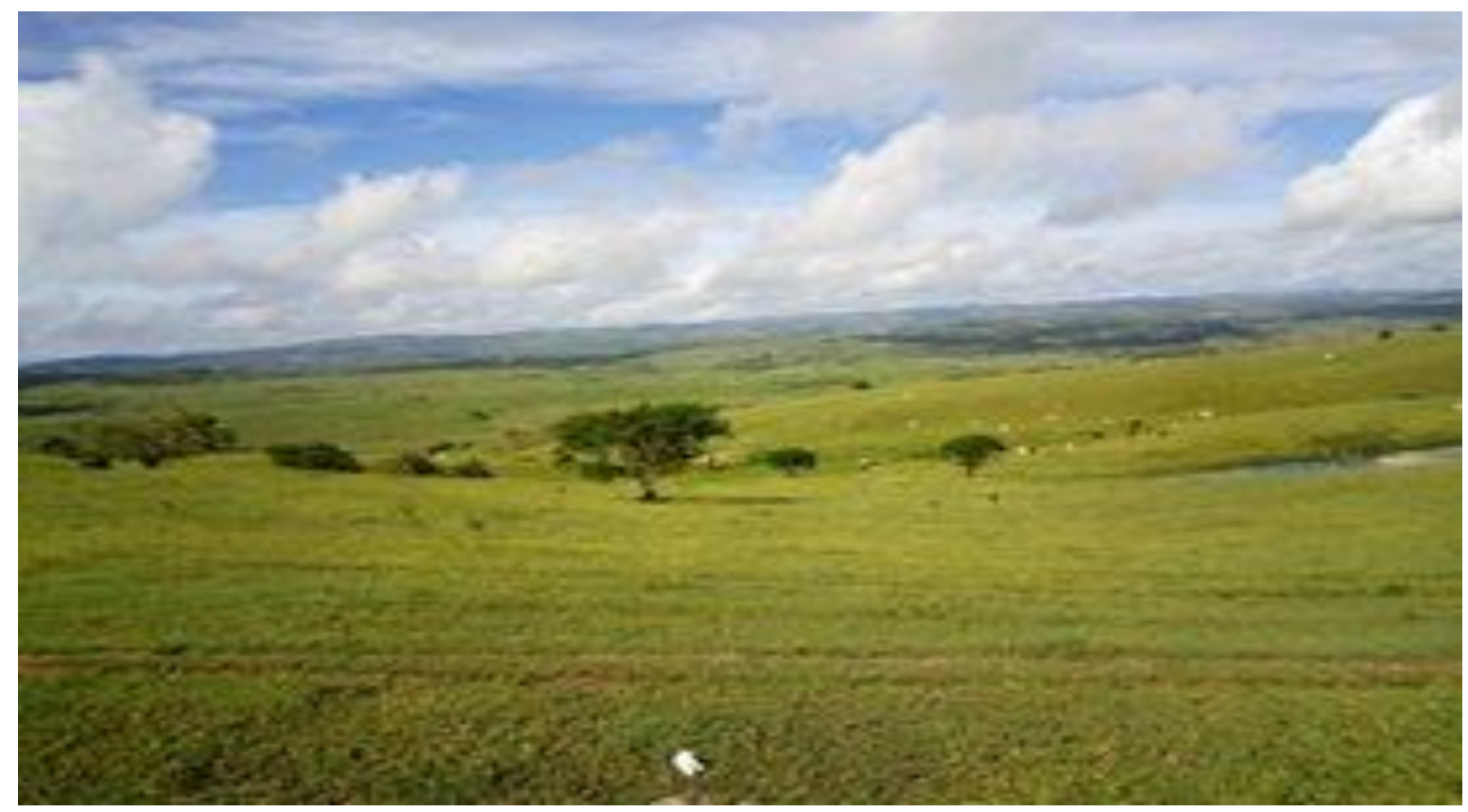

Figura 4. Fotografia de uma área de pastagem onde permanecem algumas espécies de Mimosa tenuiflora, conhecida como jurema preta. Madeira que apresenta capital natural de grande valor para cercamento da propriedade, evidenciando um grande desmatamento impulsionado pela cultura da produção de leite. Fonte: Autores.

\section{CONSIDERAÇÕES FINAIS}

Quando o fator econômico prevalece, o ser humano, influenciado pela ânsia de obter novos capitais, acaba degradando os recursos cada vez mais escassos. Com a atividade agropecuária, necessitou-se de mais pastagem e para isso o desmatamento foi inevitável. Porém, este ocorreu de maneira predatória, danificando as populações de plantas e consequentemente reduzindo a diversidade fitogeográfica. É preciso impor limites às ações antrópicas, não sendo admitida que essa vasta riqueza seja depreciada pela ignorância econômica que corrompe a vitalidade humana. Necessita-se recrudescer em nós a consciência e a responsabilidade de que se continuarmos a exploração da diversidade fitogeográfica com tal ritmo, todo o potencial fitossociológico terá se expirado. 


\section{REFERÊNCIAS}

DA SILVA, Luiz Fernando Tavares Cardoso et al. DEGRADAÇÃO AMBIENTAL EM ÁREAS DESTINADAS À PECUÁRIA NA SUB-BACIA HIDROGRÁFICA DÓ RIO SANA, MACAÉ-RJ. Revista de Geografia (Recife), v. 29, n. 1, p. 45-59, 2012.

DE ANDRADE LIMA. Dárdano. Estudos fitogeográficos de Pernambuco.Anais da academia Pernambucana de ciência agronômica, v. 4, p. 243-274, 2014.

DE OLIVEIRA COSTA, Jorge Luis Paes. FITOGEOGRAFIA DO PARQUE NACIONAL SERRA DA CAPIVARA/PIAUÍ-BRASIL: INVESTIGAÇÕES PRELIMINARES.

JÚNIOR, Caio Prado. História econômica do Brasil. Editora brasiliense, 1978.

SALES, Vanda de Claudino. Geografia, sistemas e análise ambiental: abordagem crítica. GEOUSP: espaço e tempo, n. 16, p. 125-141, 2011.

VIADANA, A. G. Biogeografia: natureza, propósitos e tendências. In: Reflexões sobre a geografia física no Brasil. A. C. VITTE \& A. J. T. GUERRA (Orgs.) Rio de janeiro: Bertrand Brasil, 2004.

Recebido em: 14/08/2016

Aceito para publicação em: 01/10/2016 